- Dental pain is a public health problem that affects $28 \%$ of the UK adult population.

- Amongst those reporting dental pain, young men from lower socio-economic groups are less likely to access professional dental treatment, and more likely to report dental treatment need.

- The dental needs of this particular group should be addressed if the Government is to live up to its commitment to reducing oral health inequality and improving access.

\title{
Demographic and socio-economic correlates of dental pain among adults in the United Kingdom, 1998
}

\author{
A. Pau, ${ }^{1}$ R. E. Croucher ${ }^{2}$ and W. Marcenes ${ }^{3}$
}

Objective To report the demographic and socio-economic correlates for dental pain in UK adults, and characterise those with dental pain who did not access dental services and perceived treatment need. Design Secondary analysis of the 1998 UK Adult Dental Health Survey data.

Setting Survey of random sample of UK households between September and December 1998.

Subjects and methods Face-to-face interviews with communitydwelling adults, aged 16 years and over.

Main outcome measures Self-reported dental pain in the past 12 months. Dental attendance and perceived treatment need of those reporting dental pain.

Results Of the 4,942 valid responses, 46.1\% were men, the proportion of subjects in each 10-year band age group up to 65 years ranged from 10 to $23 \%$, and $42.6 \%$ were manual workers. Dental pain was reported by $28 \%$. After controlling for gender and age, manual workers were more likely to report dental pain $(\mathrm{OR}=1.21,95 \% \mathrm{Cl}=1.06-1.37)$, non-utilisation of dental services $(\mathrm{OR}=1.43,95 \% \mathrm{Cl}=1.12-1.82)$, and perceived treatment need $(\mathrm{OR}=1.28,95 \% \mathrm{Cl}=1.03-1.60)$.

Conclusions Inequality by social class, age and gender exists in the experience of dental pain, access to dental services and perceived treatment need in the UK adult population. Dental health services need to address the needs of this particular section of the population if the Government is to live up to its commitment to reducing oral health inequality and improving access.

Senior Lecturer, ${ }^{2}$ Professor of Community Oral Health, ${ }^{3}$ Professor of Oral Epidemiology, Centre for Adult Oral Health, Institute of Dentistry, Barts and The London, Queen Mary's School of Medicine and Dentistry, Queen Mary, University of London, Turner Street, London, E1 2AD

${ }^{*}$ Correspondence to: Dr Allan Pau

Email:a.k.pau@qmul.ac.uk

Online article number E21

Refereed Paper - accepted 15 June 2006

DOI: $10.1038 /$ bdj.2007.171

${ }^{\circledR}$ British Dental Journal 2007; 202: E21

\section{INTRODUCTION}

Although dental pain affects a significant proportion of the population, ${ }^{1-5}$ and has considerable impact on their quality of life ${ }^{6-10}$ and dental utilisation, ${ }^{11-13}$ its distribution by demographic and socio-economic characteristics is not well documented. Vargas et al. ${ }^{14}$ have identified, from a national survey of the American adult population, that tooth pain while biting or chewing in the past six months is more commonly reported by younger adults, or those with less education or with incomes below poverty when compared with older adults, or those with higher education or income. National surveys of the oral health of adults in the United Kingdom have been carried out every ten years since 1968 but the distribution of dental pain by demographic and socio-economic characteristics has not been documented. Although it is acknowledged that inequality in oral health and access to dental services are two major challenges for NHS dentistry in the United Kingdom, ${ }^{15}$ there has been no published data to demonstrate inequality in the experience of dental pain, which is increasingly recognised as a significant and common dimension of oral health status and quality of life. ${ }^{16}$ Furthermore, the demographic and socio-economic correlates of the use of dental services and perception of treatment need amongst those with dental pain are not known. This paper aims to report the demographic and socio-economic distribution for dental pain by analysing data collected in the UK Adult Dental Health Survey (ADHS) 1998. It also aims to characterise, amongst those reporting dental pain, respondents who did not utilise professional dental services and who perceived a need for dental treatment.

\section{METHODS}

Data source

Data for this study were taken from the 1998 UK Adult Dental Health Survey, which is the national data source currently available that has information on dental pain. There were two elements to this cross-sectional survey: 1 ) a face-to-face interview to collect information on the respondent's oral health 


\begin{tabular}{|c|c|c|c|c|c|c|}
\hline & \multicolumn{2}{|c|}{$\begin{array}{l}\text { Painful aching in the past } 12 \text { months: } \\
n(\%)\end{array}$} & \multicolumn{2}{|c|}{ Unadjusted OR } & \multicolumn{2}{|c|}{ Adjusted OR } \\
\hline & No & Yes & $p$-value & $(95 \% \mathrm{Cl})$ & $p$-value & (95\% Cl) \\
\hline Total & $3,542(72)$ & $1,400(28)$ & & & & \\
\hline \multicolumn{7}{|l|}{ Gender } \\
\hline Male & $1,679(74)$ & $600(26)$ & & 1 & & 1 \\
\hline Female & $1,863(70)$ & $800(30)$ & 0.004 & $1.20(1.06-1.36)$ & 0.001 & $1.24(1.09-1.41)$ \\
\hline \multicolumn{7}{|l|}{ Age group } \\
\hline $16-24$ & $332(67)$ & $160(33)$ & 0.001 & $2.28(1.73-3.02)$ & 0.001 & $2.24(1.69-2.96)$ \\
\hline $25-34$ & 778 (70) & $339(30)$ & 0.001 & $2.06(1.62-2.63)$ & 0.001 & $2.03(1.60-2.59)$ \\
\hline $35-44$ & $722(67)$ & 355 (33) & 0.001 & $2.33(1.83-2.97)$ & 0.001 & $2.32(1.82-2.96)$ \\
\hline $45-54$ & 708 (71) & $288(29)$ & 0.001 & $1.93(1.51-2.47)$ & 0.001 & $1.93(1.50-2.47)$ \\
\hline $55-64$ & $481(76)$ & $148(24)$ & 0.008 & $1.45(1.11-1.92)$ & 0.009 & $1.45(1.10-1.91)$ \\
\hline $65+$ & $521(83)$ & $110(17)$ & & 1 & & 1 \\
\hline \multicolumn{7}{|l|}{ Social class } \\
\hline Manual & $1,470(70)$ & $634(30)$ & 0.015 & $1.17(1.03-1.32)$ & 0.004 & 1.21 (1.06-1.37) \\
\hline Non-manual & 2,072 (73) & 766 (27) & & 1 & & 1 \\
\hline
\end{tabular}

behaviour, attitudes and opinions; and 2) for respondents with some natural teeth, a home dental examination. ${ }^{17}$ The fieldwork took place between September and December 1998. Data were collected from a multi-stage stratified random sample.

The outcome variables in this paper were self-reported dental pain, use of professional dental service and perceived need for dental treatment. Self-reported dental pain was measured by the question: 'In the last 12 months, that is, since $\{D A T E\}$, have you had painful aching in your mouth?' The responses were dichotomised into two groups, that is, those who reported 'never or hardly ever' and those who reported 'occasional to very often'. Use of professional dental services was determined by asking respondents whether they had been to the dentist in the last 12 months. Perceived need for dental treatment was assessed by asking subjects whether they thought they would need treatment if they went to the dentist tomorrow.

Other variables of interest included in the analysis were gender, age and social class. Respondents were categorised into age groups of 10-year bands from 16-25 years, up to 65 years. Social class was categorised into manual or non-manual. The number of subjects in the survey was 6,764, of whom 955 did not respond to the question on social class and 12 were in the armed forces. Of the remaining 5,797 subjects, 4,942 responded to the question on painful aching, all were dentate.

Data analysis testing the association between self-reported 'painful aching in the mouth' and socio-demographic characteristics was conducted on 4,942 subjects. The likelihood of reporting painful aching was assessed with odds ratios derived from logistic regression models. Odds ratios, with 95\% confidence intervals, were used to indicate how many times one particular group was more likely to report painful aching when compared to a reference group. The significance level was set at $p<0.05$. Of those reporting painful aching, analysis was carried out between utilisation of professional dental services, perceived dental treatment need and socio-demographic characteristics. Logistic regression analysis was carried out to characterise those who did not attend a dentist in the past 12 months and those who perceived a need for dental treatment if they went to the dentist tomorrow.

\section{RESULTS}

4,942 valid responses were analysed. Of these, 46.1\% were men, 10.0\% were aged 16-24, 22.6\% aged 25-34, 21.8\% aged 35-44, 20.2\% aged 45-54, 12.7\% aged 55-64 and 12.8\% aged 65 years and over. Manual workers comprised $42.6 \%$ of the sample.

'Painful aching in the mouth' in the past 12 months was reported by $28 \%$, with women significantly more likely than men to report dental pain in the past 12 months $(\mathrm{OR}=1.20$, $95 \% \mathrm{CI}=1.06-1.36)$. Those in the younger age groups were more likely to report dental pain when compared to the reference group of 65 years and over. Dental pain was also more likely to be reported by subjects in the manual social class $(\mathrm{OR}=1.17,95 \% \mathrm{CI}=1.03-1.32)$. Logistic regression analysis indicated that gender, age and social class were independently associated with self-reported dental pain (Table 1).

Amongst those who reported dental pain in the past 12 months, men compared to women $(\mathrm{OR}=1.63$, 95\% CI $=1.28$ $2.06)$, those in the $16-24(\mathrm{OR}=2.67,95 \% \mathrm{CI}=1.52-4.69)$ and 25-34 (OR $=1.70,95 \% \mathrm{CI}=1.01-2.86)$ age groups compared to those in the $65+$ group, and those in the manual social class (OR $=1.57,95 \% \mathrm{CI}=1.24-1.99)$ were more likely to report that they had not visited a dentist in the past 12 months. Logistic regression analysis indicated that all three variables were 
independently associated with non-utilisation of professional dental services in the past 12 months (Table 2).

Amongst those who reported dental pain in the past 12 months, men compared to women $(\mathrm{OR}=1.63,95 \% \mathrm{CI}=1.31$ 2.03) and those in the younger age groups compared to the reference group of 65+ were more likely to report needing treatment if they went to the dentist tomorrow. Those in the manual compared to non-manual social class $(\mathrm{OR}=1.38,95 \%$ $\mathrm{CI}=1.11-1.71)$ were more likely to report perceived treatment need. Logistic regression analysis indicated that all three variables were independently associated with self-reported perceived treatment need (Table 3).

\section{DISCUSSION}

This paper aimed to identify the demographic and socio-economic correlates of self-reported dental pain, and characterise those who had not attended a dentist in the past 12 months and those with perceived treatment need by analysing data collected in the Adult Dental Health Survey 1998. ${ }^{17}$ The main findings are that dental pain was reported by $28 \%$ of the sample. Women, younger adults and those in the manual social class were more likely to report dental pain when compared to men, older adults and non-manual social class. Of those who reported dental pain, men, younger adults and those in the manual social class were more likely to report not using professional dental services in the past 12 months. Men, younger adults and those in the manual social class were more likely to report perceived need for dental treatment. After controlling for gender and age, those in the manual social class were significantly more likely to report dental pain, non-attendance at the dentist and perceived treatment need.

The prevalence estimate of $28 \%$ for painful aching is comparable to that of $27 \%$ for dental pains reported for an
American population. ${ }^{1}$ A more recent national survey of community-dwelling Americans adults aged 20 years and over has estimated a prevalence of $12 \%$ for 'toothache when biting or chewing in the past 6 months', ${ }^{4}$ Studies using Canadian adults have reported 14\% for 'toothache' and 29\% for 'pain in teeth with hot and cold fluids or sweet things' over a fourweek period, ${ }^{2}$ and 33\% for 'oral pain symptoms in the previous four weeks. ${ }^{5}$ Analysis of this dataset indicated that women are more likely to report painful aching. This is consistent with the results of a Nigerian survey on toothache ${ }^{18}$ although other studies have documented that men are more likely to report dental pain ${ }^{19}$ or oral pain. ${ }^{20}$ In contrast, Vargas et al. ${ }^{14}$ did not report an association between tooth pain and gender. The variation in the prevalence estimates reported and inconsistency in the reports of distribution by gender may be due to the descriptions used for dental pain. The lack of consensus in the translation of dental pain into lay descriptions for epidemiological purposes makes it difficult to compare different studies.

Consistent with a previous report on American adults, ${ }^{14}$ analysis of the present dataset suggests that older adults are less likely to report dental pain when compared to younger adults. Recent studies have also indicated that younger adults are more likely to express experiences of dental pain ${ }^{19}$ when compared to older adults, and increasing age has been reported to be associated with decreased reporting of 'toothache'. ${ }^{21}$ Older people are also more likely to report 'pain to hot and cold', whereas younger people are more likely to report 'toothache'. This is expected because older people suffer more from exposed dentine due to recession, whereas younger people suffer more from pulpitis. Other reasons may be related to lower expectations for oral health later in life so that a certain amount of pain is accepted, ${ }^{22}$ to the presence of a lower number of teeth at risk of pain among older adults. ${ }^{2}$

Table 2 Socio-demographic correlates of those who did not attend a dentist amongst those reporting dental pain in the past 12 months $(n=1,400)$

\begin{tabular}{|c|c|c|c|c|c|c|}
\hline & \multicolumn{2}{|c|}{ Visited dentist in the last 12 months } & \multicolumn{2}{|c|}{ Unadjusted OR } & \multicolumn{2}{|c|}{ Adjusted OR } \\
\hline & Yes & No & $\mathrm{p}$-value & $(95 \% \mathrm{Cl})$ & $\mathrm{p}$-value & $(95 \% \mathrm{Cl})$ \\
\hline Total & $1,026(73)$ & $374(27)$ & & & & \\
\hline \multicolumn{7}{|l|}{ Gender } \\
\hline Male & $407(68)$ & $193(32)$ & 0.001 & $1.63(1.28-2.06)$ & 0.001 & $1.53(1.98-1.96)$ \\
\hline Female & $619(77)$ & $181(23)$ & & 1 & 0.001 & 1 \\
\hline \multicolumn{7}{|l|}{ Age group } \\
\hline $16-24$ & $96(60)$ & $64(40)$ & 0.001 & $2.67(1.52-4.69)$ & 0.001 & $2.61(1.48-4.62)$ \\
\hline 25-34 & $238(70)$ & $101(30)$ & 0.047 & $1.70(1.01-2.86)$ & 0.035 & $1.76(1.04-2.98)$ \\
\hline $35-44$ & $267(75)$ & $88(25)$ & 0.303 & $1.32(0.78-2.23)$ & 0.298 & $1.33(0.78-2.25)$ \\
\hline $45-54$ & $222(77)$ & $66(23)$ & 0.531 & $1.19(0.69-2.04)$ & 0.518 & $1.20(0.69-2.07)$ \\
\hline $55-64$ & $115(78)$ & $33(22)$ & 0.656 & $1.15(0.63-2.11)$ & 0.636 & $1.16(0.63-2.14)$ \\
\hline $65+$ & $88(80)$ & $22(20)$ & & 1 & & 1 \\
\hline \multicolumn{7}{|l|}{ Social class } \\
\hline Manual & 434 (68) & $200(32)$ & 0.001 & $1.57(1.24-1.99)$ & 0.005 & $1.43(1.12-1.82)$ \\
\hline Non-manual & $592(77)$ & $174(23)$ & & 1 & & 1 \\
\hline
\end{tabular}




\begin{tabular}{|c|c|c|c|c|c|c|}
\hline & \multicolumn{2}{|c|}{$\begin{array}{l}\text { Need treatment if went to } \\
\text { dentist tomorrow }\end{array}$} & \multicolumn{2}{|c|}{ Unadjusted OR } & \multicolumn{2}{|c|}{ Adjusted OR } \\
\hline & No & Yes & $p$-value & $(95 \% \mathrm{Cl})$ & $\mathrm{p}$-value & $(95 \% \mathrm{Cl})$ \\
\hline Total & $581(41)$ & $819(59)$ & & & & \\
\hline \multicolumn{7}{|l|}{ Gender } \\
\hline Male & 209 (35) & $391(65)$ & 0.001 & $1.63(1.31-2.03)$ & 0.001 & $1.58(1.26-1.97)$ \\
\hline Female & $372(47)$ & $428(53)$ & & 1 & & 1 \\
\hline \multicolumn{7}{|l|}{ Age group } \\
\hline $16-24$ & $54(34)$ & $106(66)$ & 0.001 & $2.54(1.54-4.18)$ & 0.001 & $2.50(1.51-4.15)$ \\
\hline 25-34 & $119(35)$ & $220(65)$ & 0.001 & $2.39(1.54-3.70)$ & 0.001 & $2.50(1.60-3.89)$ \\
\hline $35-44$ & $152(43)$ & $203(57)$ & 0.013 & $1.73(1.12-2.66)$ & 0.012 & $1.74(1.13-2.69)$ \\
\hline $45-54$ & $116(40)$ & $172(60)$ & 0.004 & $1.92(1.23-2.99)$ & 0.004 & $1.93(1.24-3.03)$ \\
\hline $55-64$ & $78(53)$ & $70(47)$ & 0.559 & $1.16(0.71-1.90)$ & 0.531 & $1.17(0.71-1.94)$ \\
\hline $65+$ & $62(56)$ & $48(44)$ & & 1 & & 1 \\
\hline \multicolumn{7}{|l|}{ Social class } \\
\hline Manual & 236 (37) & 398 (63) & 0.003 & $1.38(1.11-1.71)$ & 0.028 & $1.28(1.03-1.60)$ \\
\hline Non-manual & $345(45)$ & $421(55)$ & & 1 & & 1 \\
\hline
\end{tabular}

A noteworthy finding from the present analysis is the association between dental pain and socio-economic status, as measured by professional classification, reflecting the unequal distribution of oral and general health that has been consistently reported in the literature. Data from the 1989 American National Health Interview Survey ${ }^{14}$ suggested that self-reported tooth pain was more common in those with low levels of education (0-11 years), below the poverty threshold and who were uninsured for health services when compared to their counterparts. More recently, lower socio-economic status $^{23}$ and not being financially comfortable ${ }^{21}$ have been reported to be associated with reporting dental pain. Amongst those reporting dental pain in the past twelve months, an association was identified between socio-economic status, and use of professional dental services and perceived treatment need. Despite reporting dental pain, there remained a group of individuals, significantly more men than women, younger compared to older adults, and manual compared to non-manual workers who reported that they had not accessed a dentist in the past 12 months, and who perceived a need for dental treatment if they were to visit the dentist tomorrow. Logistic regression analysis, controlling for gender and age, indicated that social class was a significant independent predictor for non-utilisation of professional dental services and perceived treatment need. The findings that dental services were more commonly accessed by men compared to women ${ }^{24}$ and by those having higher education compared to those having low education ${ }^{25}$ have been reported. Concern over the dental care of young adults and the demographic and economic factors that influence access has been expressed, but little research has been done on their use of dental services. ${ }^{24}$ Although the literature suggests that younger adults more commonly report dental pain, most researchers have focussed on the oral health needs of older adults and their patterns of dental utilisation. ${ }^{26,27}$ Results of this analysis have identified a group of young male adults from the non-manual social class who do not access professional dental care despite reporting dental pain and who perceived a need for dental treatment. Oral health inequality and access to dental services are two challenges that face UK dentistry. ${ }^{15}$ The UK Adult Dental Health Survey data suggest that there is inequality in the experience of dental pain and access to dental services for certain disadvantaged groups in the community. In order to address these issues, further research is needed to explore the reasons for non-attendance so that appropriate dental services may be planned to cater for this need.

\section{CONCLUSIONS}

Dental pain is a public health problem affecting some $28 \%$ of the UK adult population. It is unequally distributed by gender, age and social class. In addition, young men from the manual social class are less likely to access professional dental treatment despite reporting dental pain, and more likely to express a perceived need for dental treatment. The barriers to access as perceived or experienced by this group of young adults need to be identified in order that dental services may be more equitably planned and provided. Dental health services need to address the needs of this particular section of the population if the Government is to live up to its commitment to reducing oral health inequality and improving access.

This paper has been produced with the permission of the Office for National Statistics. Social Survey Division, Adult Dental Health Survey (ADH), 1998 [computer file]. Colchester, Essex: UK Data Archive [distributor], November 2000. SN: 4226. The findings presented are based on secondary analysis of work undertaken by a consortium comprising the Office for National Statistics and the Dental Schools of the Universities of Birmingham, Dundee, Newcastle and Wales who received funding from the United Kingdom 
Health Departments; the views expressed in this publication are those of the authors and not necessarily those of the Health Departments nor of the other members of the consortium.

1. Sternbach RA. Survey of pain in the United States: The Nuprin Pain Report. Clin J Pain 1986; $2:$ 49-53

2. Locker D, Grushka M. Prevalence of oral and facial pain and discomfort: preliminary results of a mail survey. Community Dent Oral Epidemiol 1987; 15: 169-172.

3. Brattberg G. Thorslund M, Wikman A. The use of common pain experiences in designing a pain intensity scale for epidemiological purposes. J Psychosom Res 1988; 32: 505-512.

4. Lipton J A, Ship J A, Larach-Robinson D. Estimated prevalence and distribution of reported orofacial pain in the United States. J Am Dent Assoc 1993; 124: 115-121.

5. Locker D, Miller Y. Evaluation of subjective oral health status indicators. J Public Health Dent 1994; 54: 167-176.

6. Kressin N, Spiro A, Bosse R, Garcia R, Kazis L. Assessing oral health-related quality of life. Findings from the Normative Aging Study. Med Care 1996; 34: 416-427.

7. Gilbert G H, Duncan R P, Vogel W B. Determinants of dental care use in dentate adults: six-monthly use during a 24-month period in the Florida dental care study. Soc Sci Med 1998; 47: 727-737.

8. Srisilapanan P, Sheiham A. The prevalence of dental impacts on daily performances in older people in Northern Thailand. Gerodontology 2001; 18: 102-108.

9. Chavers LS, Gilbert G H, Shelton B J. Two-year incidence of oral disadvantage a measure of oral health-related quality of life. Community Dent Oral Epidemiol $2003 ; 31: 21-29$.

10. Needleman I, McGrath C, Floyd P, Biddle A. Impact of oral health on the life quality of periodontal patients. J Clin Periodontol 2004; 31: 454-457.

11. Holtzman J M, Berkey A B, Mann J. Predicting utilization of dental services by the aged. J Public Health Dent 1990; 50: 164-171.

12. Ekanayake L, Mendis R. Self-reported use of dental services among employed adults in Sri Lanka. Int Dent J 2002; 52: 151-155.

13. Duncan R P, Gilbert G H, Peek C W, Heft M W. The dynamics of toothache pain and dental services utilization: 24-month incidence. J Public Health Dent 2003;
63: 227-234

14. Vargas C M, Macek M D, Marcus S E. Sociodemographic correlates of tooth pain among adults: United States, 1989. Pain 2000; 85: 87-92.

15. Department of Health. Modernising NHS dentistry - implementing the NHS plan. London: Department of Health, 2000.

16. Slade G D. Measuring oral health and quality of life. Chapel Hill: University of North Carolina, 1997.

17. Kelly M, Steele J, Nuttall N et al. Adult dental health survey: oral health in the United Kingdom 1998. London: The Stationery Office, 2000.

18. Okunseri C, Hodges J S, Born D. Self-reported toothache experience in an adult population in Benin City, Edo State, Nigeria. Oral Health Prev Dent 2005; 3: $119-125$.

19. Alkhatib M N, Gilthorpe M S, McGrath C. Disparities in self reported oral health problems among a young Syrian adult population. Int Dent J 2002; 52: 449-452.

20. Reid B C, Chenette R, Macek M D. Prevalence and predictors of untreated caries and oral pain among Special Olympic athletes. Spec Care Dentist 2003. 23: 139-142.

21. Ringland C, Taylor L, Bell J, Lim K. Demographic and socio-economic factors associated with dental health among older people in NSW. Aust N Z J Public Health 2004; 28: 53-61.

22. Atchison K A, Gift H C. Perceived oral health in a diverse sample. Adv Dent Res 1997; 11: 272-280

23. Riley J L 3rd, Gilbert $G H$, Heft M W. Socioeconomic and demographic disparities in symptoms of orofacial pain. J Public Health Dent 2003; 63: 166-173.

24. Roberts-Thomson K F, Stewart J F. Access to dental care by young South Australian adults. Aust Dent J 2003; 48: 169-174.

25. Mumcu G, Sur H, Yildirim C, Soylemez D, Atli H, Hayran O. Utilisation of dental services in Turkey: a cross-sectional survey. Int Dent J 2004; 54: 90-96.

26. Dolan T A, Atchison K, Huynh T N. Access to dental care among older adults in the United States. J Dent Educ 2005; 69: 961-974.

27. Department of Health. Meeting the challenges of oral health for older people: a strategic review. Gerodontology 2005; 22 Suppl 1:3-48. 